\title{
Study on Influencing Factors of Forestry Economic Growth in Guangdong Province Based on Grey Correlation Analysis
}

\author{
Hongjie Gao, Xiaowen Zheng*, Xiaoling Li, Qiujv Huang, Shengfu Lin \\ College of Economy and Trade, Zhongkai University of Agriculture and Engineering, Guangzhou Guangdong 510225, \\ China \\ *Corresponding author. Email: 694632654@qq.com
}

\begin{abstract}
Based on the data of guangdong rural statistical yearbook (2011-2018) and guangdong statistical yearbook (2011-2018), the grey correlation analysis method was used to analyze the factors influencing the growth of forestry economy in guangdong province. The results show that the correlation between GDP and forestry economic growth $>$ The correlation between afforestation area and forestry economic growth and the correlation between sunshine hours in $>$ and forestry economic growth $>$ The correlation between population density and forestry economic growth $>$ The correlation between forest coverage rate and forestry economic growth $>$ The correlation between annual average temperature and forestry economic growth $>$ The correlation between average annual rainfall and forestry economic growth > The correlation between the number of forestry workers and the growth of forestry economy $>$ The correlation between total forestry investment and forestry economic growth.
\end{abstract}

Keywords: Grey correlation analysis; Guangdong province; Forestry economic growth; Factors affecting the

\section{INTRODUCTION}

Economic development problem is the center of gravity of economics research, the related research of forestry economy is also the focus of economics field. Guangdong province is a large forestry province in south China. As one of the basic industries of national economy, the forestry industry of guangdong province plays an important role in promoting the economic development of guangdong province. The forestry industry will bring some social and ecological benefits as well as economic benefits. Since the reform and opening, the development of forestry of guangdong province into an important transition period, through ten years of afforestation in guangdong, forestry ecological county forestry second startup and create development strategies, such as guangdong province forestry gradually by the past into a foundational industry attaches great importance to the economic growth, environmental protection and sustainable development of the combination of comprehensive industry, the forestry economic construction has made remarkable achievements. The no. 1 document of the central committee of 2018 pointed out that the modern and efficient development of forestry in China should be accelerated and actions should be taken to invigorate the forests and enrich the people. The 2019 guidelines on giving priority to agricultural and rural development and doing a good job in agriculture, rural areas and farmers emphasizes the need to deepen the reform of collective forest tenure and forest farms in state-owned forest districts. The three-year action plan for promoting the development of forestry in the guangdong-hong kong-macao greater bay area (2018-2020) released by the guangdong provincial forestry administration stipulates that the level of forest management should be comprehensively improved and the construction of national forest cities in the pearl river delta region should be accelerated. In the decision on accelerating the construction of a forestry ecoprovince, the guangdong provincial government proposed that guangdong should achieve the goal of building a forestry eco-province and a developed forestry industrial system by 2020 .Therefore, it is necessary to analyze the growth of forestry economy in guangdong province and find out the key factors that affect the development of forestry economy in guangdong province so as to promote the sustainable development of forestry economy in guangdong province. At present, many scholars have done a lot of research on the influencing factors of forestry economic growth and reached certain research conclusions.[1] According to the relevant data of China's forestry economic development from 1978 to 2011, the research using the grey relational degree model shows that forestry capital input is the main factor of China's forestry economic growth. (Zhang, Yang and Li . 2016) using DEA model, it is found that the input-output efficiency of forestry in Beijing is relatively high.[2] (Cao, et al. 2016) based on the panel data of forestry economic development in 31 provinces, it is found that factors such as forestry economic quality, forestry market potential and forestry population and capital play a major role in the development of forestry economy in all provinces.[3]( Zhao, et al. 2017) using the space panel econometric model and Moran's I index, it is found that the industrial structure, human resource input and forest 
resources play an important role in promoting the development of forestry economy in key state-owned forest areas in heilongjiang province.[4] (Zhang, Lv and Liu. 2017 ) based on the partial least square regression model, the marginal contribution of the change of forestry industry composition and the increase of factor input to the growth of heilongjiang province's forestry output value is analyzed.[5] (Jiang and Liu . 2017) based on the semi-parametric hybrid model, it is concluded that government investment has a positive external effect on forestry economic growth.[6] ( Luo et al. 2017) the dynamic analysis of the industrial structure and competitiveness of the three forest regions in the south, southwest and northeast was carried out by dynamic deviation-share analysis.[7] (Yan, Jin and Zhang . 2018) this paper studies the coordinated development mode of forestry informatization and forestry economy in China by using information economy law.[8] (Xiang, Chen and Lia. 2018) the dynamic deviation-share analysis method is used to analyze the forestry economic growth in the Yangtze river economic belt.[9] (Li and Zhang . 2018) using c-d production function and solow residual value method, it is found that the progress of forestry technology has important contribution to the increase of forestry output in China.[10] In general, scholars' methods of studying the influencing factors of forestry economic development are developing in the direction of diversification. The above analysis of the influencing factors of forestry economic development in various regions of China provides an important reference for this paper. This study is based on the forestry economic data of guangdong rural statistical yearbook (2011-2018) and guangdong statistical yearbook (2011-2018), selection of forestry output value as an indicator reflects the core of forestry economic growth in guangdong province, in the forest coverage rate, the average annual rainfall, annual average temperature, annual sunshine hours, afforestation area, regional GDP and population density, complete forestry investment and forestry on-the-job worker total number of the nine variables as explained the influencing factors of forestry economic growth in guangdong province, the grey relational model is used to analyze the relevant data and find out the main factors influencing the forestry economic growth in guangdong province.

\section{RESEARCH METHODS AND DATA SOURCES}

\subsection{RESEARCH METHOD}

The research method used in this paper is the gray system proposed by professor deng julong after a lot of experiments and research, and has been developed for quite a long time. The gray system is a system between the white system and the black system(Deng. 2002). The grey relational analysis used in this paper is an information processing system based on the grey system theory, and then studies the relationship between known information and unknown information through calculation and analysis.[11] During the application of this model, if the development trends of the two variables in the study show a consistent or synchronous trend, then the correlation between the two factors is relatively high; Otherwise, the correlation between the two is low. Therefore, gray correlation analysis is a scientific research method that finds out the same or similar development trend among variables or factors through data analysis, so as to obtain the degree of correlation between them.

\subsection{DATA SOURCE AND INFLUENCE FACTOR SELECTION}

The data used in this study are from guangdong statistical yearbook (2011-2018) and guangdong rural statistical yearbook (2011-2018), the total forestry output value is selected as the reference series and set as $X_{0}(\mathrm{k})$. Forest coverage rate, average annual rainfall, average annual temperature, annual sunshine hours, afforestation area, gross regional product, population density, total forestry investment and number of forestry workers on the job were selected as the data series composed of factors influencing the system behavior, that's comparing sequences, and set them as $X_{1}(\mathrm{k}), X_{2}(\mathrm{k}), X_{3}(\mathrm{k})$, $X_{4}(\mathrm{k}), X_{5}(\mathrm{k}), X_{6}(\mathrm{k}), X_{7}(\mathrm{k}), X_{8}(\mathrm{k})$ and $X_{9}(\mathrm{k})$ among them $\mathrm{k}=1,2,3,4,5,6,7,8$ each represents the data in the corresponding statistical yearbook from 2011 to 2018.

\section{GREY CORRELATION ANALYSIS OF INFLUENCING FACTORS OF FORESTRY ECONOMIC GROWTH IN GUANGDONG PROVINCE}

\subsection{SET UP REFERENCE SEQUENCE AND COMPARISON SEQUENCE}

According to the principle of grey correlation analysis, a reference sequence is set up $X_{0}=\left\{\mathrm{x}_{0}(\mathrm{k}), \mathrm{k}=1,2, \cdots, \mathrm{n}\right\} \quad, \quad$ to compare the sequence

$X_{\mathrm{i}}=\left\{\mathrm{xi}_{\mathrm{i}}(\mathrm{k}), \mathrm{k}=1,2, \cdots, \mathrm{n}\right\}(\mathrm{i}=1,2, \cdots, \mathrm{m})$

Combined with the data of guangdong rural statistical yearbook (2011-2018) and guangdong statistical yearbook (2011-2018), the original data summary is obtained as shown in table 1. 
Table 1 summary of the original data of factors influencing the forestry economic growth in guangdong province from 2010 to 2017

\begin{tabular}{|c|c|c|c|c|c|c|c|c|}
\hline Factor & 2010 & 2011 & 2012 & 2013 & 2014 & 2015 & 2016 & 2017 \\
\hline $\begin{array}{c}\text { Total forestry } \\
\text { output value }(\$ 100 \\
\text { million) } X_{0}\end{array}$ & 2802.16 & 3328.1 & 4691 & 5595 & 6500 & 7150 & 7696 & 8022 \\
\hline $\begin{array}{l}\text { Land area covered } \\
\text { with trees }(\%) \\
X_{1}\end{array}$ & 57 & 57.3 & 57.7 & 58.2 & 58.69 & 58.88 & 58.98 & 59.08 \\
\hline $\begin{array}{c}\text { Average annual } \\
\text { rainfall (mm) } \\
X_{2}\end{array}$ & 1867.7 & 1336.8 & 1847.6 & 2124.5 & 1652.5 & 1845.7 & 2321 & 1710.7 \\
\hline $\begin{array}{l}\text { Annual average } \\
\text { temperature } \\
\text { (Celsius) } X_{3}\end{array}$ & 21.9 & 21.58 & 21.8 & 21.9 & 22.1 & 22.6 & 22.3 & 22.4 \\
\hline $\begin{array}{c}\text { Annual sunshine } \\
\text { hours (hours) } \\
X_{4}\end{array}$ & 1647 & 1862.2 & 1547.9 & 1715.1 & 1836 & 1735.8 & 1622 & 1757.3 \\
\hline $\begin{array}{c}\text { Afforestation area } \\
\text { (thousands of } \\
\text { hectares) } X_{5}\end{array}$ & 95.14 & 125.48 & 107.5 & 139.06 & 151.47 & 123 & 101 & 81 \\
\hline $\begin{array}{l}\text { Gross Domestic } \\
\text { Product }(\$ 100 \\
\text { million) } X_{6}\end{array}$ & $\begin{array}{c}46013.0 \\
6\end{array}$ & $\begin{array}{c}53210.2 \\
8\end{array}$ & $\begin{array}{c}57067.9 \\
2\end{array}$ & $\begin{array}{c}62163.9 \\
7\end{array}$ & $\begin{array}{c}67809.8 \\
5\end{array}$ & $\begin{array}{c}72812.5 \\
5\end{array}$ & $\begin{array}{c}79512.0 \\
5\end{array}$ & $\begin{array}{c}89705.2 \\
3\end{array}$ \\
\hline $\begin{array}{c}\text { Population density } \\
\text { (population / km2) } \\
\qquad X_{7}\end{array}$ & 581 & 584 & 590 & 593 & 597 & 604 & 612 & 621 \\
\hline $\begin{array}{c}\text { Total forestry } \\
\text { investment } \\
\text { completed } \\
(\$ 10,000) X_{8}\end{array}$ & 77995 & 505088 & 636673 & 983675 & 732897 & 967229 & 790191 & 817000 \\
\hline $\begin{array}{c}\text { Number of active } \\
\text { staff (persons) } \\
X_{9}\end{array}$ & 35916 & 32260 & 31294 & 31271 & 29685 & 30424 & 26265 & 25526 \\
\hline
\end{tabular}

Data source: Guangdong Rural Statistical Yearbook (2011-2018), Guangdong Statistical Yearbook (2011-2018) 


\subsection{DIMENSIONLESS DATA PROCESSING}

During the study of one or more sets of data, because the data in each factor in the system is inconsistent in terms of dimensions, there will be some uncontrollable factors in the process of comparing the data, affecting the final result stability. Therefore, when conducting gray correlation analysis, the necessary processing must be performed on the research data, so that the data appears dimensionless and normalized, the common methods for dimensionless processing in gray correlation analysis are averaging, initialization, etc. The initialization method is selected in this paper. According to the formula: $Y_{\mathrm{i}}(\mathrm{k})=\frac{X_{\mathrm{i}}(\mathrm{k})}{X_{\mathrm{i}}(1)}(\mathrm{i}=1,2, \cdots, \mathrm{n})$

data on the raw economic sequence obtained $X_{0}, X_{1}, X_{2}, X_{3}, X_{4}, X_{5}$, $X_{6}, X_{7}, X_{8}$ and $X_{9}$ initialize to get the corresponding $Y_{0}, Y_{1}, Y_{2}, Y_{3}, Y_{4}, Y_{5}, Y_{6}$, $Y_{7}, Y_{8}$ and $Y_{9}$. the dimensionless processing results of the data are shown in table 2.

Table 2 Data dimensionless processing results

\begin{tabular}{ccccccccc}
\hline $\begin{array}{c}\text { Fact } \\
\text { or }\end{array}$ & 2010 & 2011 & 2012 & 2013 & 2014 & 2015 & 2016 & 2017 \\
\hline$Y_{0}$ & 1.0000 & 1.1877 & 1.6741 & 1.9967 & 2.3196 & 2.5516 & 2.7465 & 2.8628 \\
$Y_{1}$ & 1.0000 & 1.0053 & 1.0123 & 1.0211 & 1.0296 & 1.0330 & 1.0347 & 1.0365 \\
$Y_{2}$ & 1.0000 & 0.7157 & 0.9892 & 1.1375 & 0.8848 & 0.9882 & 1.2427 & 0.9159 \\
$Y_{3}$ & 1.0000 & 0.9854 & 0.9954 & 1.0000 & 1.0091 & 1.0320 & 1.0183 & 1.0228 \\
$Y_{4}$ & 1.0000 & 1.1307 & 0.9398 & 1.0413 & 1.1148 & 1.0539 & 0.9848 & 1.0670 \\
$Y_{5}$ & 1.0000 & 1.3189 & 1.1299 & 1.4616 & 1.5921 & 1.2928 & 1.0616 & 0.8514 \\
$Y_{6}$ & 1.0000 & 1.1564 & 1.2403 & 1.3510 & 1.4737 & 1.5824 & 1.7280 & 1.9496 \\
$Y_{7}$ & 1.0000 & 1.0052 & 1.0155 & 1.0207 & 1.0275 & 1.0396 & 1.0534 & 1.0688 \\
$Y_{8}$ & 1.0000 & 6.4759 & 8.1630 & 12.6120 & 9.3967 & 12.4012 & 10.1313 & 10.4750 \\
$Y_{9}$ & 1.0000 & 0.8982 & 0.8713 & 0.8707 & 0.8265 & 0.8471 & 0.7313 & 0.7107
\end{tabular}

Source: This study

$\Delta_{\mathrm{i}}=\left(\Delta_{\mathrm{i}}(1), \Delta_{\mathrm{i}}(2), \cdots, \Delta_{\mathrm{i}}(\mathrm{k})\right) \quad, \quad$ which
$\Delta_{\mathrm{i}}(\mathrm{k})=\left|Y_{0}(\mathrm{k})-Y_{\mathrm{i}}(\mathrm{k})\right|, \quad(\mathrm{i}=0,1,2, \cdots, \mathrm{n})$, results as follows:

$\Delta_{1}=(0.0000,0.1824,0.6618,0.9756$,

$1.2900,1.5186,1.7117,1.8263$ )
Ask for this $Y_{0}$ and $Y_{\mathrm{i}}$ difference between $\Delta_{\mathrm{i}}$, Poor sequence 
$\Delta_{2}=(0.0000,0.4719,0.6848,0.8592,1.4349$, $1.5634,1.5037,1.9469)$

$\Delta_{3}=(0.0000,0.2023,0.6786,0.9967,1.3105$, $1.5196,1.7282,1.8400)$

$\Delta_{4}=(0.0000,0.0570,0.7342,0.9553,1.2049$, $1.4977,1.7616,1.7958)$

$\Delta_{5}=(0.0000,0.1312,0.5442,0.5350,0.7276$, $1.2588,1.6849,2.0114)$

$\Delta_{6}=(0.0000,0.0313,0.4338,0.6457,0.8459$, $0.9692,1.0184,0.9132)$

$\Delta_{7}=(0.0000,0.1825,0.6586,0.9760,1.2921$, $1.5120,1.6931,1.7939)$

$\Delta_{8}=(0.0000,5.2882,6.4889,10.6154$,

$7.0771,9.8496,7.3849,7.6122)$

$\Delta_{9}=(0.0000,0.2895,0.8028,1.1260,1.4931$, $1.7045,2.0152,2.1521$ )

Based on differential sequence $\Delta_{\mathrm{i}}$ find the two-stage minimum difference and the maximum difference. Order the First Layer Minimum Value $\min \Delta_{\mathrm{i}}(\mathrm{k})$, Maximum order $\max \Delta_{i}(\mathrm{k})$, as follows:

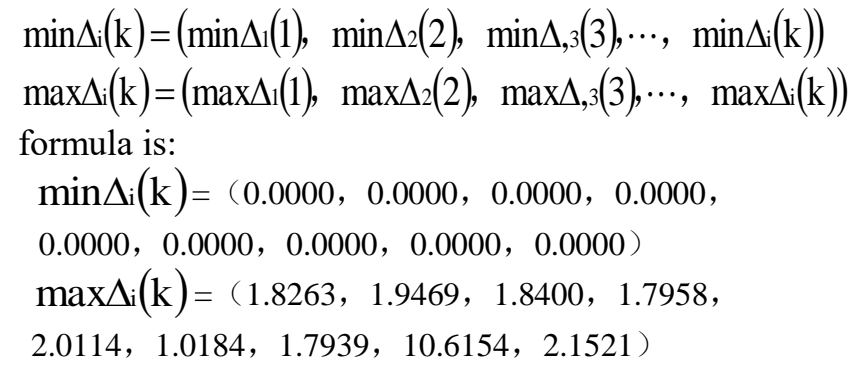

According to the minimum sequence $\min \Delta_{\mathrm{i}}(\mathrm{k})$ and maximum sequence $\max \Delta_{i}(\mathrm{k})$ the result is calculated as the minimum difference and the maximum difference between the two levels $\mathrm{m}$, The maximum difference is $\mathrm{M}$, as follows:

$$
\begin{gathered}
\mathrm{m}=\min \left(\min \Delta_{\mathrm{i}}(\mathrm{k})\right)=0.0000 \\
\mathrm{M}=\max \left(\max \Delta_{\mathrm{i}}(\mathrm{k})\right)=10.6154
\end{gathered}
$$

\subsection{CALCULATE CORRELATION COEFFICIENT}

According to the principle of grey correlation analysis model, Comparison sequence $X_{\mathrm{i}}$ Reference sequence $X_{0}$ when $\mathrm{k}$ grey correlation coefficient of the moment $\xi_{1}(\mathrm{k})$ formula is: $\xi_{1}(\mathrm{k})=\frac{\min \left(\min \Delta_{\mathrm{i}}(\mathrm{k})\right)+\rho \max \left(\max \Delta_{\mathrm{i}}(\mathrm{k})\right)}{\left|X_{\mathrm{o}}(\mathrm{k})-X_{\mathrm{i}}(\mathrm{k})\right|+\rho \max \left(\max \Delta_{\mathrm{i}}(\mathrm{k})\right)}$

which $\rho$ for resolution coefficients, and $\rho \in[0,1]$, In this study, the resolution coefficient is taken $\rho=0.5$. The $\xi(\mathrm{k})$ formula to:

$$
\xi(\mathrm{k})=\frac{\mathrm{m}+\rho M}{\Delta_{\mathrm{i}}(\mathrm{k})+\rho M}=\frac{0+0.5 \times 10.6154}{\Delta_{\mathrm{i}}(\mathrm{k})+0.5 \times 10.6154}=\frac{5.3077}{\Delta_{\mathrm{i}}(\mathrm{k})+5.3077}
$$

Put $\quad \Delta_{1} \sim \Delta_{9}$ data substitution formula

$$
\xi(\mathrm{k})=\frac{5.3077}{\Delta_{\mathrm{i}}(\mathrm{k})+5.3077}
$$

coefficients as follows:

$$
\text { calculated correlation }
$$

$\xi_{1}=(1.0000,0.9668,0.8891,0.8447$,

$0.8045,0.7775,0.7561,0.7440)$

$\xi_{2}=(1.0000,0.9183,0.8857,0.8607$,

$0.7872,0.7725,0.7792,0.7316)$

$\xi_{3}=(1.0000,0.9633,0.8866,0.8419$,

$0.8020,0.7774,0.7544,0.7426)$

$\xi_{4}=(1.0000,0.9894,0.8785,0.8475$,

$0.8150,0.7799,0.7508,0.7472)$

$\xi_{5}=(1.0000,0.9759,0.9070,0.9084$,

$0.8794,0.8083,0.7590,0.7252)$

$\xi_{6}=(1.0000,0.9941,0.9244,0.8915$,

$0.8625,0.8456,0.8390,0.8532)$

$\xi_{7}=(1.0000,0.9668,0.8896,0.8447$,

$0.8042,0.7783,0.7582,0.7474)$

$\xi_{8}=(1.0000,0.5009,0.4499,0.3333$,

$0.4286,0.3502,0.4182,0.4108)$

$\xi_{9}=(1.0000,0.9483,0.8686,0.8250$,

$0.7804,0.7569,0.7248,0.7115)$

\subsection{CALCULATION OF CORRELATION}

Collect the correlation coefficients at each time (that is, the points in the curve) into a single value, that is, find the average value, and use this as the quantitative expression of the degree of correlation between the comparison sequence and the reference sequence, correlation formula $r_{i}$ is calculated as:

$$
\mathrm{r}_{\mathrm{i}}=\frac{1}{\mathrm{n}} \sum_{\mathrm{k}=1}^{\mathrm{n}} \xi_{\mathrm{i}}(\mathrm{k}), \mathrm{k}=1,2, \cdots, \mathrm{n}
$$

$r_{1}, r_{2}, r_{3}, r_{4}, r_{5}, r_{6}, r_{7}, r_{8}, r_{9}$ Respectively, forest coverage and the correlation of forestry economic growth, with an average annual rainfall of forestry, annual average temperature of correlation between economic growth and forestry, annual sunshine time of correlation between economic growth and forest, afforestation area of correlation between economic growth and the correlation of forestry economic growth, regional GDP and correlation of forestry economic growth, population density and forestry, forestry investment total completion of correlation between economic growth and forestry and forestry on-the-job worker number of correlation between economic growth and correlation of forestry economic 
growth. According to the calculation formula of correlation degree $\mathrm{r}_{\mathrm{i}}$ :

$$
\begin{aligned}
& r_{1}=0.8478 \\
& r_{2}=0.8419 \\
& r_{3}=0.8460 \\
& r_{4}=0.8510 \\
& r_{5}=0.8704 \\
& r_{6}=0.9013 \\
& r_{7}=0.8486 \\
& r_{8}=0.4865 \\
& r_{9}=0.8269
\end{aligned}
$$

\subsection{RANKING BY CORRELATION DEGREE}

According to the obtained value, rank $r_{i}$ in a certain order according to the value of correlation degree. The higher the value of $\mathrm{r}_{i}$, the higher the correlation degree. On the contrary, the smaller the value of $r_{i}$, the lower the correlation degree. The sorting results are as follows:

$$
\mathrm{r}_{6}>\mathrm{r}_{5}>\mathrm{r}_{4}>\mathrm{r}_{7}>\mathrm{r}_{1}>\mathrm{r}_{3}>\mathrm{r}_{2}>\mathrm{r}_{9}>\mathrm{r}_{8}
$$

\section{ANALYSIS OF EMPIRICAL RESULTS}

The empirical analysis shows that $\mathbf{r}_{6}>\mathbf{r}_{5}>\mathbf{r}_{4}>\mathbf{r}_{7}>\mathrm{r}_{1}>\mathrm{r}_{3}>\mathrm{r}_{2}>\mathrm{r}_{9}>\mathrm{r}_{8}$ namely the correlation degree of gross regional product and forestry economic growth $>$ The correlation between afforestation area and forestry economic growth $>$ The correlation between annual sunshine hours and forestry economic growth $>$ The correlation between population density and forestry economic growth $>$ The correlation between forest coverage rate and forestry economic growth $>$ The correlation between annual average temperature and forestry economic growth > The correlation between average annual rainfall and forestry economic growth $>$ The correlation between the number of forestry workers and the growth of forestry economy $>$ The correlation between total forestry investment and forestry economic growth. From the calculation results, the forest coverage rate, annual average rainfall, annual average temperature, annual sunshine hours, afforestation area, gross regional product, population density and number of forestry workers have a great correlation with the growth of forestry economy in guangdong province. Among them, the correlation between GDP and guangdong forestry economic growth is 0.9013 , which is highly correlated with each other. To improve the forestry economic growth of guangdong province, we can focus on this aspect. In addition, the correlation between afforestation area, annual sunshine hours, population density, forest coverage, annual average temperature, annual average rainfall and the number of onthe-job forestry employees is slightly lower than that of forestry economic growth, and the coefficients between GDP and forestry economic growth are $0.8704,0.8510,0.8486$, $0.8478,0.8460,0.8419$ and 0.8269 respectively, which are also important factors affecting the forestry economic growth of Guangdong Province. The result shows that the relationship between the total forestry investment and the forestry economic growth is small $(0.4865)$, which is weaker than other factors.

\section{CONCLUSION}

Through the correlation analysis of factors affecting the growth of the forestry economy in Guangdong Province, the following conclusions are drawn: GDP has the greatest correlation with Guangdong's forestry economic growth, The total completed forestry investment has the smallest correlation with the forestry economic growth in Guangdong Province.This inspired Guangdong Province to vigorously promote economic development, thereby enhancing the growth of forestry economy.

\section{ACKNOWLEDGMENT}

Fund project:Innovation fund for college students of Zhongkai University of Agriculture and Engineering in 2019“An Empirical Study on Consumers' Purchasing Intention of Camellia Oil in Qingyuan City" ( Project Number: 2019A35)

\section{REFERENCES}

[1]KE Shui-fa, CHEN Zhang-chun, ZHAO Tie-rui. Factors Influencing China's Forest Economic Growth Based on Grey Correlation Model[J]. Journal of AgroForestry Economics and Management, 2014, 13(03): 281 290.

[2]ZHANG Ying, YANG Gui-hong, LI Zhuo-wei. Analysis of input-output efficiency of forestry in Beijing based on DEA model[J]. Journal of Beijing Forestry University, 2016, 38(02): 105-112.

[3]CAO Yan, HE Dong-jin, JI Zhi-rong, HONG Wei, Lian Su-lan. Spatial Panel Econometric Analysis of the Influential Factors of Forestry Economic Development in China[J]. Forestry Economics, 2016, 38(05): 66-70+90.

[4]ZHAO Xiao-guang, ZHAO Jia-huan. Spatial Panel Analysis on Factors Influencing Forestry Economic Development in Key State-owned Forested Areas in Heilongjiang Province[J]. Journal of Zhejiang Forestry Science and Technology, 2017, 37(05): 54-60.

[5]ZHANG Bin, LV Jie-hua, LIU Yan-di. Research on Forestry Economic Growth Problems in Heilongjiang Province_ - on the Perspectives of Industrial Structure and Factors Input[J]. Forestry Economics, 2017, 39(12): 31-37. 
[6]JIANG Wei, LIU Jun-chang. Relationship between Forestry Economic Growth and Government Investment Based on Semiparametric Mixed Model[J]. Jiangsu Agricultural Sciences, 2017, 45(12): 270-274.

[7]Luo Xiaofeng, Wang Zejun, Li Zhaoliang, Xue Longfei. Forestry Industrial Structure Transformation and Its Contribution to Economy $[\mathrm{J}]$. Statistics and Decision, 2017(14): 93-97.

[8]YAN Xing-yu, Jin Zhaohuai, Zhang Qingzheng. Analysis and Countermeasures of the Relationship between Forestry Informationization and Forestry Economic Development in China[J].Inquiry Into Economic Issues, 2018(03): 151-158.

[9]XIANG Hong-ling, CHEN Zhao-jiu, LIAO Wen-mei. Analysis of Forestry Economic Growth, Industrial Structure Evolution and Differences in the Yangtze River Economic Belt[J].Problems of Forestry Economics, 2018, 38(05): 44$51+105$.

[10]LI Yan, ZHANG Da-hong. Empirical Analysis of the Impact of Factor Input on Forestry Economic Growth[J].Statistics and Decision, 2018, 34(15): 133-135.

[11]DENG Ju-long.Grey theory basis[M]. Wuhan: Huazhong University of Science and Technology Press, 2002. 